\title{
Pitfalls of E-education: from multimedia to digital dementia?
}

\author{
R. Robert Gajewski \\ Warsaw University of Technology \\ Al. Armii Ludowej 16, 00-637 \\ Warszawa, Poland \\ Email: rg@il.pw.edu.pl
}

\begin{abstract}
This paper presents lessons learned from nearly 25 years long experiences with different forms of E-education. All experiences are definitely positive but during conducted research many pitfalls and traps were recognized and observed. Widely used multimedia materials do not motivate weak students to learn. Instead of learning they do prefer to watch materials in a passive way. Mobile learning in which all materials are available also for smartphones increased this attitude to learning. All quizzes and tests even very sophisticated cannot replace a real exam. Knowledge of the answers on hundreds of questions is not equal to the real knowledge of a certain field. Flipped classroom paradigm forcing to learn at home was not accepted by students. Moreover, E-education creates chances for e-cheating. All these pitfalls and traps lead to the conclusion that E-education is not a straightforward remedy for all current education problems.
\end{abstract}

\section{INTRODUCTION}

N 450 B.C Confucius aid: "tell me and I will forget, show me and I may remember, involve me and I will understand." As outlined by many researchers individuals remember much more details and information as well as for longer if they are more involved in the learning process. In 1946 Dale published his famous Cone of Experience [1]. Dale stated that the cone device can be a visual metaphor of learning experiences, where the different kinds of audiovisual materials are arranged in the order of increasing abstractness as one proceeds from direct experiences (see Fig. 1). One of the later extensions of this idea is a common opinion that individuals generally remember: $10 \%$ of what they read, $20 \%$ of what they see, $50 \%$ of what they see and hear, $70 \%$ of what they say and write and $90 \%$ of what they say as they perform a task. Moreover, the entire process of learning is split into two parts: passive learning and active learning.

Blooms Taxonomy proposed in 1956 [2] by a panel of educators chaired by Benjamin Bloom is a categorization of learning objectives as well as activities split up into three areas: cognitive (mental skills, knowledge), affective (feelings, emotional areas and attitude) and psychomotor (manual and physical skills). The cognitive domain most

This work was supported by 504/01921/1088/40 grant. significant in higher education requires mental abilities and also knowledge. Within this domain one can find six major categories outlined from the most straightforward: knowledge, comprehension, application, analysis, synthesis and finally evaluation.

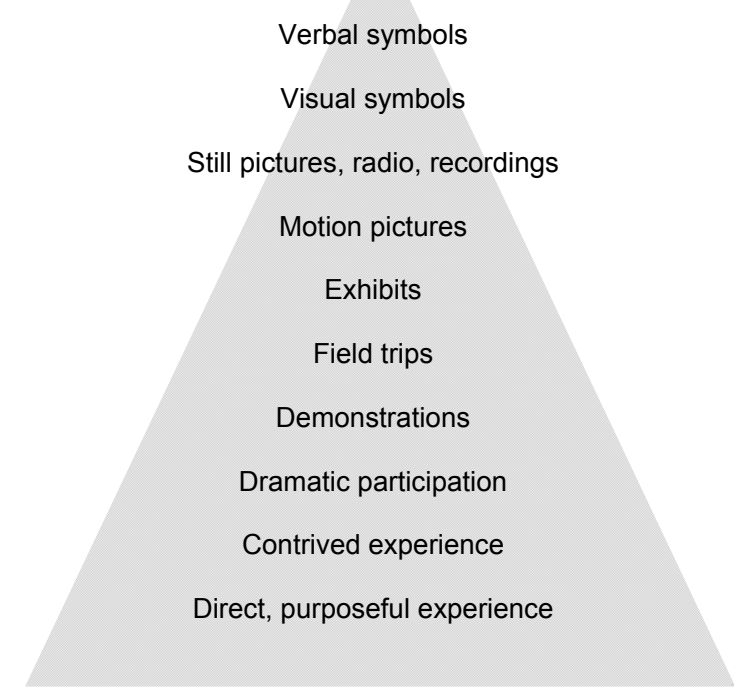

Fig. 1. Dale Cone of Experience

In the middle of 1990's the cognitive domain has been modified. Titles associated with different types have been transformed from nouns to verbs. Moreover, their order has been somewhat changed. Bloom's Revised Taxonomy [3] demonstrates to a greater extent the active way of thinking and also consists of six different categories: remembering, understanding, applying, analyzing, evaluating and finally creating. This taxonomy much better accounts for completely new behaviors and multimedia technology innovations (see Fig. 2).

E-education enables to take into account different learning styles [4]. Such approach increases costs of education but also increases its efficiency. In the class "one type of delivery" should satisfy all participants. E-education enables addressing different materials for different learning styles [5], [6] even for Computer Science and Informatics Courses. 


\section{MULTIMEDIA}

Multimedia materials were prepared for all subjects taught by the Division of Information Technologies (DoIT), namely Information Technologies, Fundamentals of Computing and Computational Methods in Civil Engineering in the form of podcasts - personal on demand broadcasts. First podcasts prepared by DoIT had the form of screencasts - "digital recordings of computer screen output often containing audio narration". Screencasts contain software animations helping students to learn how to use software. The second kind of podcasts are slidecasts "audio podcasts combined with slideshow". Slidecasts have the form of knowledge clips - short explanatory presentations of a particular problem and its solution. The last kind of multimedia materials prepared by DoIT are webcasts - "media presentations distributed over the Internet using streaming media technology to many simultaneous viewers". In fact webcasts were lecture captures which were recorded and later distributed as podcasts. Tenths of hours of podcasts stored on an educational portal helped a lot during classes but did not have an expected impact on quality of learning process measured in terms of grades obtained by students.

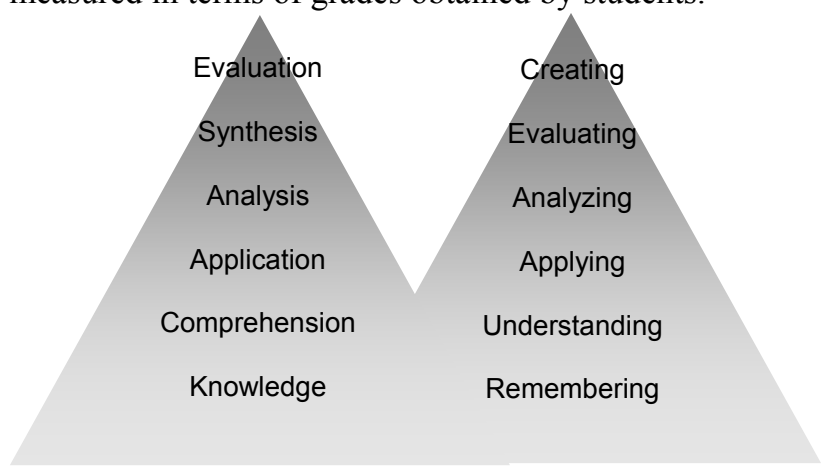

Fig. 2. Bloom's Revised Taxonomy

First podcasts were prepared in a Flash format. Nowadays this format is not available for iOS and the newest version of Android so for current mobile devices. All Flash podcasts were converted to the MP4 format or created from scratch. Now on the YouTube channel there are more than 200 clips. Their total length exceeds 50 hours.

Questionnaires performed in the academic year 2011/12 showed that having a full range of podcasts not all of students were fully satisfied by them. They were pleased by the quality and ease of use as well as by their availability in the mode 24/7. Moreover, they stressed positively that such an approach addressed different learning styles. However, in additional field of questionnaire reserved for remarks some of the students complained that the part of computer laboratories was boring for them because they repeated what was recorded in screencasts. All podcasts were designed as an additional, supplementary and auxiliary tool and all teaching and learning activities were conducted in a traditional way. Students were "taught" at the university how to use software and they were supposed to solve individual problems at home. In many cases solving problems was too difficult for them.

Starting from the academic year 2012-2013 in some of the groups podcasts were used in a different way. Students were asked to watch podcasts at home. During classes they should be prepared to use software without any problems and to solve particular problems using it. First results of this experiment were to some extend promising - students gained better scores in this mode, but they were not very keen to spend time at home watching podcasts. Students do prefer to "be taught" during classes. This problem can be easily solved by adding a simple point to subject regulations students should be prepared to computer laboratories and this fact is checked by means of a test before the class. In fact, according to European Credit Transfer System (ECTS) an average student should spend learning at home the same amount of time as at the university. It is much more effective to watch passive by nature screencasts at home and solve problems with a tutor in the class than the other way round.

\section{FLIPPED CLASSROOM}

Idea of inverting education is already nearly fifteen years old. One of the first papers in that field was published in 2000 [7]. This paper describes two parts of subject taught at Miami University while using the inverted classroom concept and analyzes the outcomes. Numerous technologies offered completely new possibilities for students to learn away from the classroom, while a school period was used to perform collaborative experiments and worksheets. Authors of the paper concluded that the idea of inverted classroom offers alternatives for various learning styles and report that students favor that strategy. A different outline and evaluation of flipped education within a huge, primarily based on lectures, computer science course was published in 2002 in [8]. In this project new multimedia and video streaming application eTech was employed to change a course. In-class lectures were substituted by recorded lectures and auxiliary materials which could be viewed by students in the Internet independently. This make it possible to utilize the live period in the class for team problem solving facilitated by tutors. Another interesting paper in that field was published one year later in 2003 [9]. Within a series of five experiments hundreds of students from two different universities supervised by three different professors and six different teaching assistants took one semester long course in the field of casual and statistical reasoning in both traditional or online format. Within the frame of this project pre and post test results were compared. Features of the online experience which were helpful and which were not helpful were identified as well as most and least effective student learning strategies. Three years later a paper evaluating a web lecture intervention in a human-computer interaction course was published [10]. By utilizing lectures available in the Web before class more inclass period was used engaging students with hands-on 
tasks. Class time was spent on learning by doing rather than learning by listening. In 2007 Gannod presented his work in progress on how to use podcasts in an inverted classroom [11]. One year later Helmick presented integrated online courseware for computer science courses [12]. Last but not least in 2008 a paper describing how to use the inverted classroom to teach software engineering was published [13]. Idea of flipped classroom was fully described in three books recently published by Bergmann and Sams [14], Bretzmann [15] and Walsh [16].

The research concerning students' satisfaction with flipped classroom was conducted in academic year 2013/2014 on a group of 222 students studying in Polish (PL) and a group of 51 students studying in English (EN). Out of $222 \mathrm{PL}$ students the questionnaire was filled by 211 students which makes $95 \%$. Similar data are for students studying in English. Questionnaire was filled by 49 out of 51 students. One third of students studying in English were foreigners.

Questionnaire used in this survey consists of fifteen closed form questions and 6 opened form questions. Due to the nature of answers all questions were divided into three groups. In order to compare the results of survey with other outcomes some of the questions were based on similar surveys: first one conducted in Canada [17] and second one described in blog Flipping with Kirch conducted by Mary Kirch from United States.

Scale of answers for all first five questions is from "strongly agree" to "strongly disagree". Results for Polish language and English language students were compared with surveys from Canada. The first of the asked questions was about the level of engagement in traditional classroom instructions and flipped classroom (see Fig. 3). The second question from that group was about potential recommendation of a flipped classroom to a friend (see Fig. 4).

$40 \%$ of students studying in Polish language strongly disagree or disagree with the statement what is in accordance with the observation, that nearly half of the students was not interested in traditional classes. Answers of students studying in English language are closer to the answers from survey conducted in Canada.

For this question answers of students studying in Polish and English languages are similar but they definitely differ from the results of survey conducted in Canada. Nearly six times more students studying in Polish language in comparison to Canadian agree or strongly agree with the statement that they would not recommend flipped classroom to a friend.

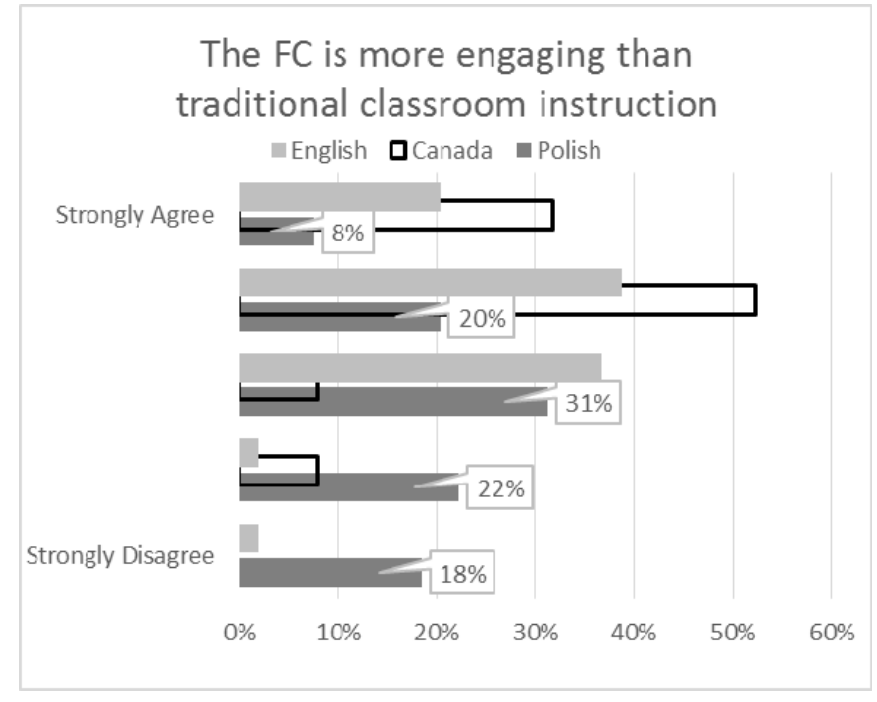

Fig. 3. Answers on question 1.1

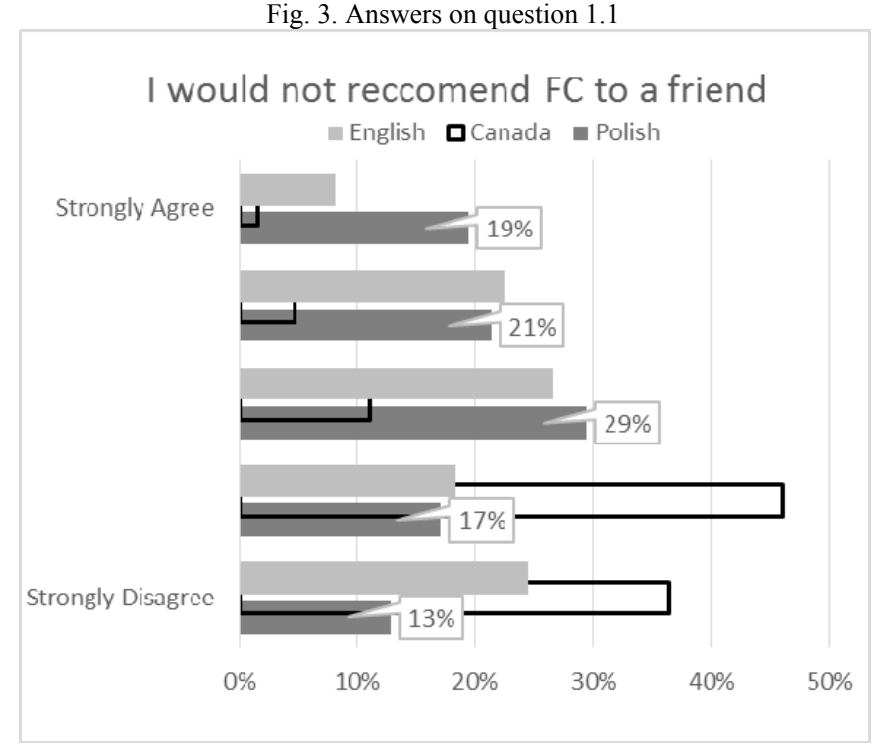

Fig. 4. Answers on question 1.2

Next question (statement) was very simple - I like watching lessons on video (see Fig. 5). In this case answers for all three groups were very similar.

Fourth question in this group of questions was about better motivation to learn in the flipped classroom mode (see Fig. 6). In the case of this question answers of students studying in Polish language differ from the answers of two other groups. Nearly $40 \%$ of them strongly disagree or disagree with that statement that they are more motivated to learn in a flipped classroom mode.

The last question in this group is about improvement of learning in the flipped classroom mode (see Fig. 7). 


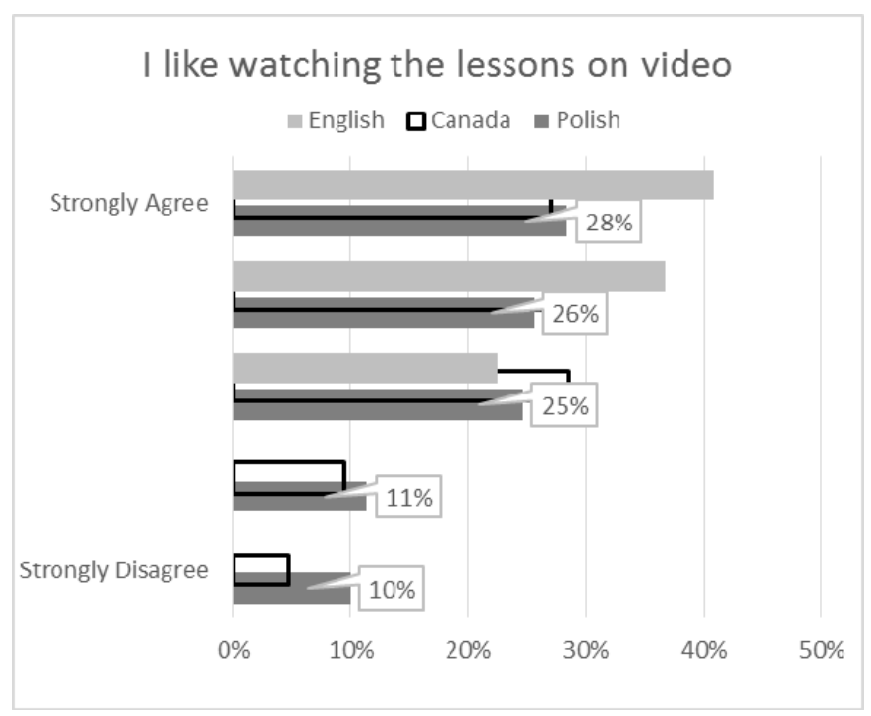

Fig. 5. Answers on question 1.3

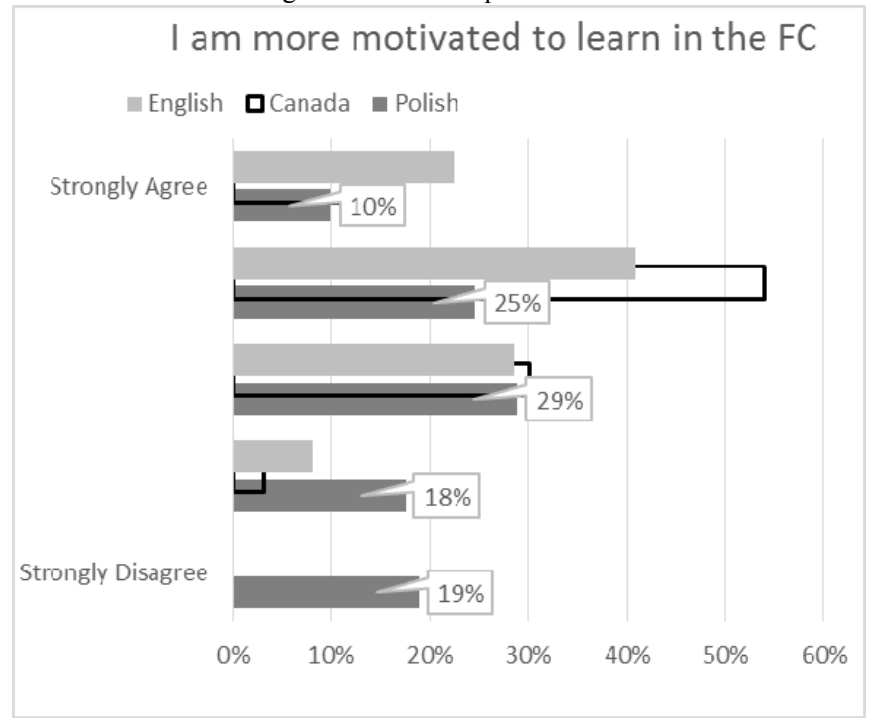

Fig. 6. Answers on question 1.4

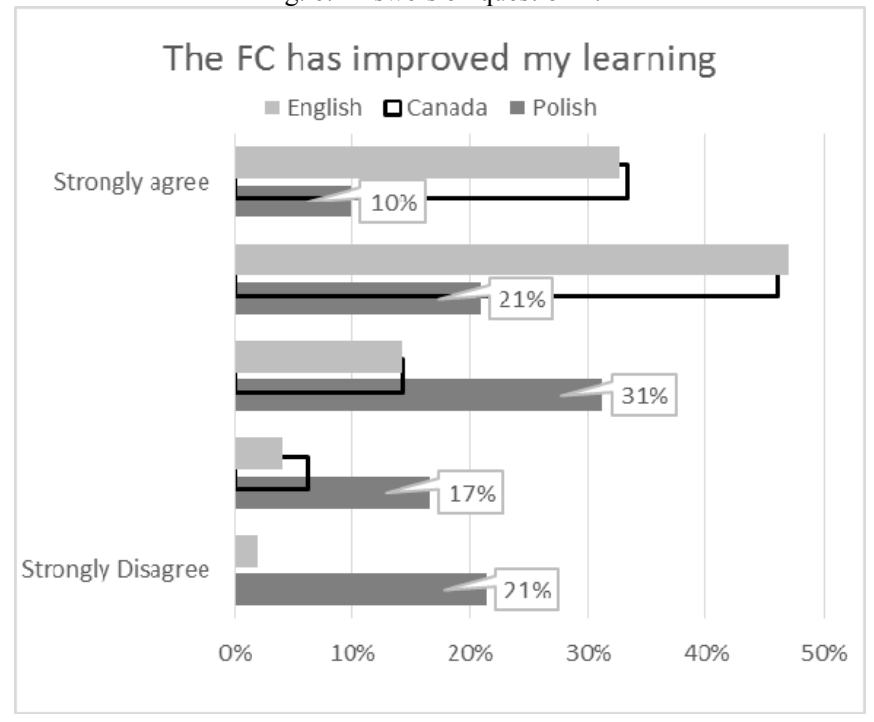

Fig. 7. Answers on question 1.5

\section{TESTS AND QUIZZES}

From the very beginning different forms of tests and quizzes were used mainly due to increasing number of students. It was not possible to check their knowledge in a classical way. Databases for subjects taught by DoIT consist of hundreds of different types of questions available on the Moodle platform like: calculated, simple calculated, calculated multi choice, description, matching, multiple choice, short-answer, numerical and True/False. After twenty years' experiences are rather sad. Students are trying to memorize answers on the questions rather than to understand the appropriate part of material. Quizzes were also used in a flipped classroom experiment. There were quick tests consisting of up to ten questions checking knowledge gained before the class at home from podcasts. Nowadays quick tests are placed at the end of classes and they force students to make notes during the class.

In order to help students to prepare for tests flashcards were used (see Fig. 8). This tool invented by Sebastian Leitner [18] can support learning treated as memorizing but rather not as understanding.

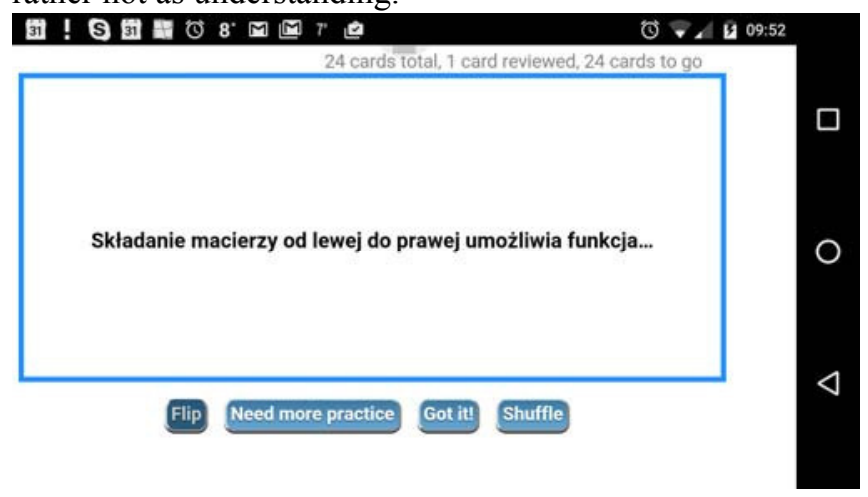

Fig. 8. Sample flashcard for mobile device

During the present academic year for traditional lectures conducted in a lecture theater at the university clickers were used. Instead of special hardware devices specialized software and smartphones were utilized (see Fig. 9).

\section{V.MOBILE LEARNING}

Shift from instructional design to e-Learning [19] was the first step of educational revolution. The next step will be devoted to transforming the system of delivery of education and training [20]. The best historical overview of m-Leaning [21] can be found in Handbook of m-Learning [22]. In the last decades there were many shifts in learning and learnercentered pedagogies and theories. Mobile courses from the field of Computer Sciences or Engineering require the usage of new and effective design strategies [23] and implementation of appropriate learning theories [24]. From a technical point of view instead of producing different applications for different mobile operating systems used on various mobile devices it is more efficient to create courses available through web browsers also on mobile devices (see Fig. 10). 


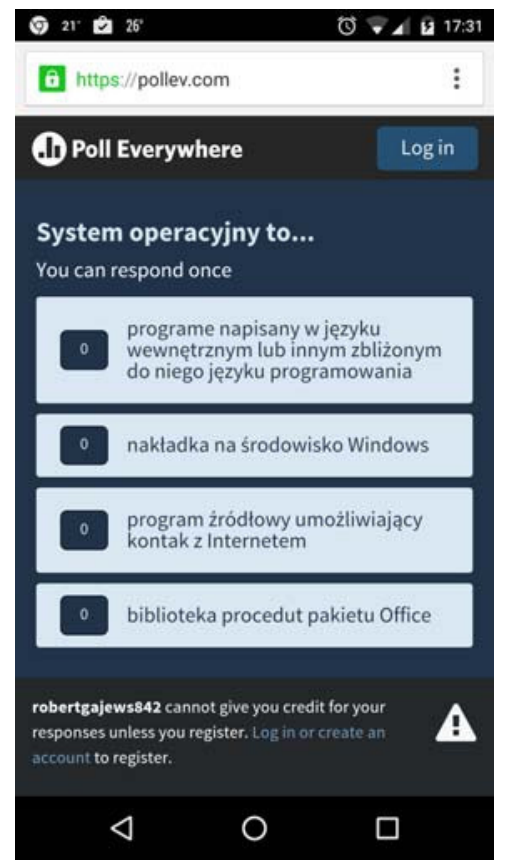

Fig. 9. Sample Poll Everywhere question

Changes in the course of engineering calculations and their programming which took place in the last few years show differences and similarities between traditional learning, e-Learning and m-Learning [25]. Regarding time traditional learning is frequently constrained by school hours, e-Learning by a time of access to computer while in the case of m-Learning in fact there are no time constraints. Learning can occur anywhere where access to the network is possible. Traditional learning is rather not personalized which contrasts with personalized e- and m-Learning. Traditional learning is definitely formal while $\mathrm{m}$-Learning is rather informal - e-Learning can be formal and informal. Last but not least traditional learning is not spontaneous while $\mathrm{m}$-Learning is highly spontaneous.

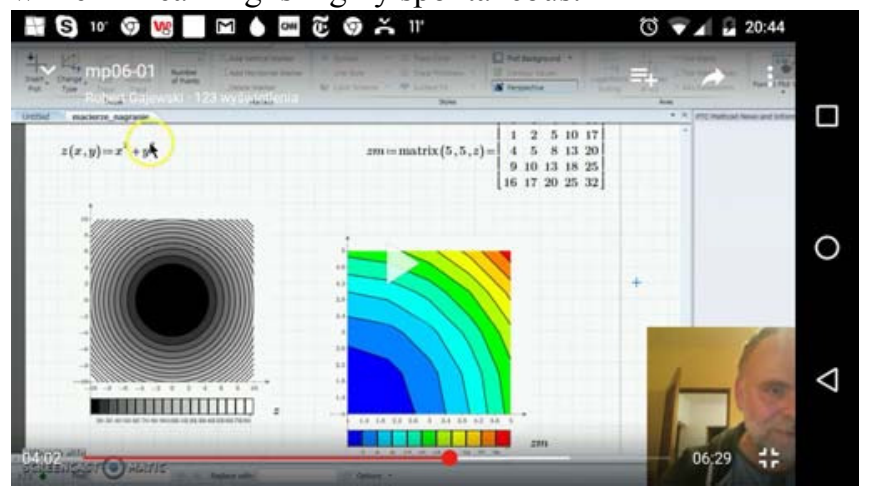

Fig. 10. Sample mobile podcast

\section{Cheating}

Cheating is perhaps as old as education. Mavis [26] wrote about college cheating as a function of subject and situational variables in 1962 and Haines [27] about college cheating as effect of immaturity, lack of commitment, and the neutralizing attitude in 1986 and also ten years later [28].
But nowadays due to the information and communication technology it is much easier to cheat so it starts to be a crucial problem. One can say that e-Learning caused eCheating as presented by Jones in [29] and in [30]. Cyber cheating is a crucial problem in an information technology age [31]. There were tenths of papers written on this subject. Their review can be found in [32]. The answer on the important philosophical question why cheating is so wrong is given in [33]. More information about this subject can also be found in [34].

In order to learn what is the attitude towards cheating among students two surveys were conducted. In order to learn what are the cultural differences between different countries first survey was based on survey from Gettysburg in USA and second was based on survey conducted in Monash University in Australia. Similar comparative analysis on students' perception and attitudes towards academic dishonesty between the students in China and United Stated was done by Zhou and Lan in [35]. Research on cheating was also conducted in Dubai [36] and in Philippines [37], [38].

The first survey was conducted during the first week of classes in October 2015 and was based on the test from Gettysburg. Total number of responses was 203. Number of students registered for the subject was 221. Total number of the questions in this survey was 24 . Answers on the question "have you ever reported another student you suspected of cheating" are rather similar (see Fig. 11).

Answers for two next questions ("have you ever interrupted a student who was cheating" and "did you ever cheat during high school") show definitely bigger differences in attitude to cheating (see Fig.12 and Fig. 13.).

\section{Have you ever reported another student you suspected of cheating?}

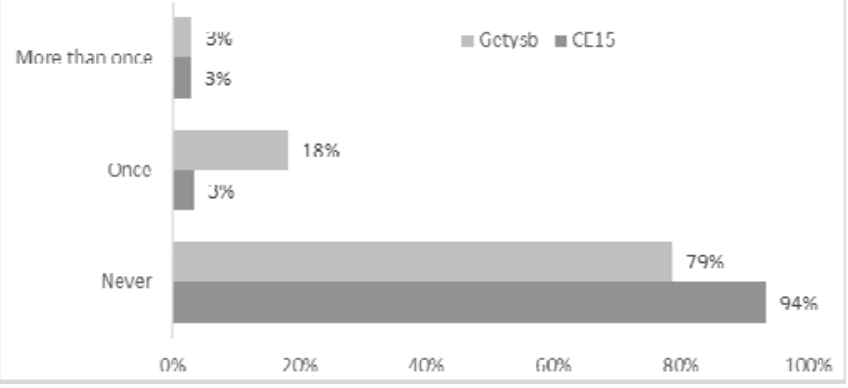

Fig. 11 Comparison of the answers on question 4 from Gettysburg survey

The second survey was conducted during the last week of classes in January 2016. Total number of responses was 179. Number of students attending classes was 201. Questionnaire of this survey is fully based on the questionnaire used in 2000 during the survey conducted in Australia at Monash University and at Swanbourne University which results were published in [39]. The same survey was conducted ten years later and results were compared in [40]. The most important part of both surveys 
consists of 18 scenarios. For each of them answers are given using Likert's scale [41] with the answers ranging from 1 acceptable to 5 - not acceptable.

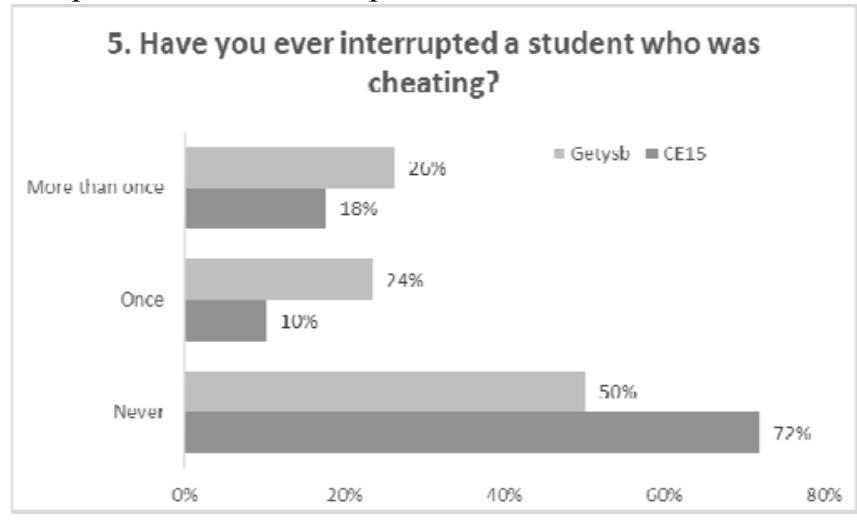

Fig. 12. Comparison of the answers on question 5 from Gettysburg survey

6. Did you ever cheat during high school?

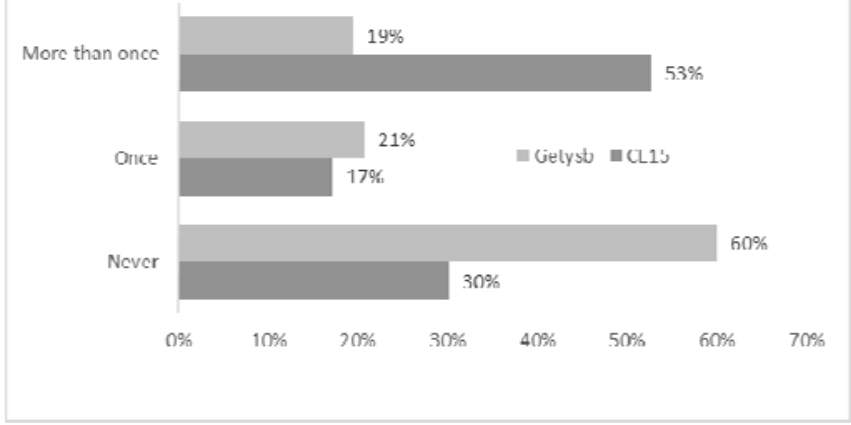

Fig. 13. Comparison of the answers on question 5 from Gettysburg survey

What can be easily learned from Table 1 is that in Australia a positive change has occurred among students over the decade with regard to cheating awareness, acceptability and practice. Results of survey conducted in Poland are much worse than Australian from the year 2000. Especially big differences are in the case of the three following scenarios:

- Copying material from the book or from the Internet,

- Swapping assignments with another person,

- Using a hidden sheet of paper with important facts during an exam.

The first problem can be generally solved by means of plagiarism checkers on the university level. The second one should be mainly solved by instructor manually. The third one which can be generally called as using unauthorized materials during exams can be solved by means of specialized IT tools. For the last mentioned scenario - using unauthorized materials - worth mentioning is a relatively small difference in mean values of acceptability $(4.59,4.64$ and 4.32$)$ and a very big difference in practice $(4 \%, 2 \%$ and $53 \%)$.

Perhaps cheating is as old as education, and the only change is in methods (see Fig. 14).

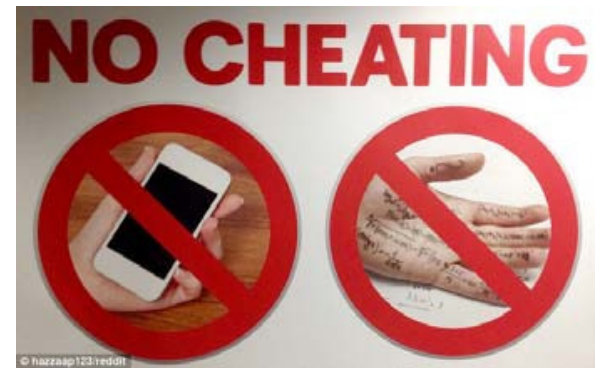

Fig. 14. No cheating

http://i.dailymail.co.uk/i/pix/2014/05/03/article-26193871D89BFD000000578-597_634x397.jpg

\section{DISCUSSION}

"Digital Dementia", a term coined by the top German neuroscientist Manfred Spitzer in his 2012 book with the same title [42], is a term used to describe how overuse of digital technology is resulting in the breakdown of cognitive abilities in a way that is more commonly seen in people who have suffered a head injury or psychiatric illness. Spitzer proposes that short-term memory pathways will start to deteriorate from underuse if we overuse technology.

Nowadays it is getting more and more important to know how does the brain work [43]. In many situations treating Internet as a natural source of information is replaced by FoMO - Fear of Missing Out [44]. Multimedia which ten years ago were a very promising educational tool nowadays make students unwilling to learn. They do prefer to watch video in a passive way rather than to learn in an active way.

Tests widely used in E-education to control knowledge are also a kind of pitfall. What is really controlled by tests this is an art of passing tests and knowledge of the answers on numerous questions. The best databases updated continuously cannot replace the teacher asking questions. Knowledge and understanding of a certain field is not equal to the knowledge how to answer on numerous questions.

Last but not least E-cheating seems to be the biggest problem in E-education. Different IT tools can make cheating more difficult but will not fully stop it.

Lessons learned from twenty five years long research in the field of e-Learning show that cultural differences should be taken into account while introducing new solutions like in the case of flipped classroom. Fifteen years after the question "how to change the unchanging" [45] was raised many things has changed. Despite all pitfalls and traps there is the only one answer on the question to be e- or not to be in the field of education. But we should be e- in a more rational way. There is still need for deep look into all three dimensions of learning [46] or how professionals learn in practice [47].

\section{ACKNOWLEDGMENT}

The author wishes to thank Marcin Jaczewski for his support during flipped classroom experiment and all surveys. Thanks are also due to Tomasz Dubilis and Tomasz 
TABLE I.

COMPARISON OF RESULTS OF SURVEYS

\begin{tabular}{|c|c|c|c|c|c|c|}
\hline \multirow[b]{2}{*}{ Scenario } & \multicolumn{3}{|c|}{ Acceptability } & \multicolumn{3}{|c|}{ Practice } \\
\hline & $\begin{array}{l}2000 \\
\text { mean }\end{array}$ & $\begin{array}{l}2010 \\
\text { mean }\end{array}$ & $\begin{array}{l}2015 \\
\text { mean }\end{array}$ & $\begin{array}{c}2000 \\
\%\end{array}$ & $\begin{array}{c}2010 \\
\%\end{array}$ & $\begin{array}{c}2015 \\
\%\end{array}$ \\
\hline Showing assignment work to a lecturer for guidance & 2.07 & 2.21 & 1.68 & 37 & 42 & 67 \\
\hline Posting to an Internet newsgroup for assistance & 2.07 & 2.28 & 1.77 & 27 & 34 & 68 \\
\hline $\begin{array}{l}\text { Two students collaborating on an assignment meant to be completed } \\
\text { individually }\end{array}$ & 2.54 & 3.20 & 2.65 & 44 & 36 & 54 \\
\hline Resubmitting an assignment from a previous subject in a new subject & 2.82 & 2.99 & 2.49 & 27 & 17 & 41 \\
\hline Submitting a friend's assignment from a past running of the subject & 2.86 & 3.46 & 3.03 & 34 & 20 & 32 \\
\hline $\begin{array}{l}\text { Copying the majority of an assignment from a friend's assignment, but doing a } \\
\text { fair bit of work yourself }\end{array}$ & 2.98 & 3.37 & 2.98 & 31 & 21 & 39 \\
\hline Not informing the tutor that an assignment has been given too high a mark & 3.08 & 3.29 & 2.82 & 17 & 16 & 39 \\
\hline $\begin{array}{l}\text { Being given the answer to a tutorial exercise worth } 5 \% \text { by a class mate if the } \\
\text { computer you used has problems }\end{array}$ & 3.76 & 4.29 & 3.03 & 7 & 3 & 9 \\
\hline Copying material for an essay from a text book & 3.81 & 4.19 & 3.71 & 22 & 10 & 34 \\
\hline Copying material for an essay from the Internet & 3.85 & 4.28 & 4.29 & 23 & 10 & 33 \\
\hline $\begin{array}{l}\text { Obtaining a medical certificate from a doctor to get an extension when you are } \\
\text { not sick }\end{array}$ & 3.94 & 4.02 & 3.35 & 12 & 3 & 9 \\
\hline $\begin{array}{l}\text { Swapping assignments with a friend, so that each does one assignment, instead } \\
\text { of doing both }\end{array}$ & 3.96 & 4.45 & 3.37 & 9 & 3 & 37 \\
\hline $\begin{array}{l}\text { Copying another student's assignment from their computer without their } \\
\text { knowledge and submitting }\end{array}$ & 4.18 & 4.62 & 3.94 & 7 & 3 & 7 \\
\hline Copying all of an assignment given to you by a friend & 4.30 & 4.62 & 3.92 & 10 & 3 & 10 \\
\hline Hiring a person to write your assignment for you & 4.51 & 4.62 & 3.97 & 3 & 1 & 6 \\
\hline Using a hidden sheet of paper with important facts during an exam & 4.59 & 4.64 & 4.32 & 4 & 2 & 53 \\
\hline Hiring someone to sit an exam for you & 4.65 & 4.69 & 4.32 & 3 & 0 & 5 \\
\hline Taking a student's assignment from a lecturer's pigeonhole and copying it & 4.72 & 4.72 & 4.29 & 4 & 2 & 3 \\
\hline
\end{tabular}

Warda from for their IT assistance. Last but not least the author wishes to thank all students who filled many very long questionnaires in the beginning and at the end of semester.

\section{REFERENCES}

[1] E. Dale, Audio-visual methods in teaching. The Dryden Press, 1946.

[2] B. S. Bloom, Taxonomy of Educational Objectives Book 1: Cognitive Domain, 2nd edition. Addison Wesley Publishing Company, 1984.

[3] L. W. Anderson, D. R. Krathwohl, P. W. Airasian, K. A. Cruikshank, R. E. Mayer, P. R. Pintrich, J. Raths, and M. C. Wittrock, A Taxonomy for Learning, Teaching, and Assessing: A Revision of Bloom's Taxonomy of Educational Objectives, Abridged Edition, 2nd ed. Pearson, 2000.

[4] R. R. Gajewski, "O stylach uczenia sie i I-edukacji," E-Mentor, vol. 3, no. 4[11], pp. 28-35, 2005.

[5] O. Mironova, T. Rüütmann, I. Amitan, J. Vilipõld, and M. Saar, "Computer Science E-Courses for Students with Different Learning Styles," in Proceedings of the 2013 Federated Conference on Computer Science and Information Systems, 2013, pp. 735-738.

[6] O. Mironova, I. Amitan, J. Vendelin, M. Saar, and T. Rüütmann, "Strategies for the Individualization of an Informatics Course," in Proceedings of the 2014 Federated Conference on Computer Science and Information Systems, 2014, vol. 2, p. pages 835-840., DOI: $10.15439 / 2014 \mathrm{~F} 259$.

[7] M. J. Lage, G. J. Platt, and M. Treglia, "Inverting the Classroom: A Gateway to Creating an Inclusive Learning Environment," J. Econ.
Educ., vol. 31, no. 1, pp. 30-43, 2000, DOI: $10.1080 / 00220480009596752$.

[8] J. Foertsch, G. Moses, J. Strikwerda, and M. Litzkow, "Reversing

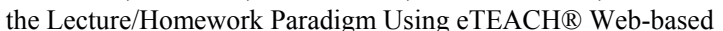
Streaming Video Software," J. Eng. Educ., vol. 91, no. 3, pp. 267 274, Jul. 2002, DOI: 10.1002/j.2168-9830.2002.tb00703.x.

[9] R. Scheines, J. Smith, G. Leinhardt, and K. Cho, "Replacing lecture with Web-based course materials," J. Educ. Comput. Res., vol. 32, pp. 1-26, 2003

[10] J. A. Day and J. D. Foley, "Evaluating a Web Lecture Intervention in a Human-Computer Interaction Course," IEEE Trans Educ, vol. 49, no. 4, pp. 420-431, Nov. 2006, DOI: 10.1109/TE.2006.879792.

[11] G. C. Gannod, "Work in progress; Using podcasting in an inverted classroom," in Frontiers In Education Conference - Global Engineering: Knowledge Without Borders, Opportunities Without Passports, 2007. FIE '07. 37th Annual, 2007, p. S3J-1-S3J-2, DOI: 10.1109/FIE.2007.4418119.

[12] M. T. Helmick, "Integrated Online Courseware for Computer Science Courses," in Proceedings of the 12th Annual SIGCSE Conference on Innovation and Technology in Computer Science Education, New York, NY, USA, 2007, pp. 146-150, DOI: $10.1145 / 1268784.1268828$.

[13] G. C. Gannod, J. E. Burge, and M. T. Helmick, "Using the Inverted Classroom to Teach Software Engineering," in Proceedings of the 30th International Conference on Software Engineering, New York, NY, USA, 2008, pp. 777-786, DOI: 10.1145/1368088.1368198.

[14] J. Bergmann, A. Sams, Flip your classroom: reach every student in every class every day. Eugene, Or: International Society for Technology in Education, 2012.

[15] J. Bretzmann, Flipping 2.0. Bretzmann Group LLC, 2013.

[16] K. Walsh and P. J. Walsh, Flipped Classroom Workshop in a Book, 1 edition. Kelly Walsh, 2013. 
[17] G. B. Johnson, "Student Perceptions on the Flipped Classroom." The University of British Columbia, 2013.

[18] D. Bryson, "Using Flashcards to Support Your Learning," J. Vis. Commun. Med., vol. 35, no. 1, pp. 25-29, Mar. 2012, doi: $10.3109 / 17453054.2012 .655720$

[19] M. W. Allen, Designing Successful e-Learning: Forget What You Know About Instructional Design and Do Something Interesting. Pfeiffer, 2007

[20] M. Ally, Ed., Mobile Learning: Transforming the Delivery of Education and Training. Athabasca University Press, 2009

[21] H. Crompton, "A Historical Overview of m-Learning," in Handbook of Mobile Learning, 1 edition., Z. L. Berge and L. Muilenburg, Eds. New York: Routledge, 2013, pp. 3-14.

[22] Z. L. Berge and L. Muilenburg, Eds., Handbook of Mobile Learning, edition. New York: Routledge, 2013.

[23] I. A. Alshalabi and K. Elleithy, "Effective M-learning design Strategies for computer science and Engineering courses," Int. J. Mob. Netw. Commun. Telemat., vol. 2, no. 1, pp. 1-11, 2012, doi: 10.5121/ ijmnct.2012.2101.

[24] I. A. Alshalabi, Sa. Hamada, and K. Elleithy, "Research Learning Theories that Entail M-Learning Education Related to Computer Science and Engineering Courses," Int. J. Eng. Sci., vol. 2, no. 3, pp. 88-95, 2013.

[25] H. Crompton, "Mobile Learning: New Approach, New Theory," in Handbook of Mobile Learning, 1 edition., Z. L. Berge and L. Muilenburg, Eds. New York: Routledge, 2013, pp. 47-58.

[26] E. Mavis and S. E. Feldman, "College cheating as a function of subject and situational variables," J. Educ. Psychol., vol. 55, no. 4, pp. 212 218, 1964, DOI: 10.1037/h0045337.

[27] V. J. Haines, G. M. Diekhoff, E. E. LaBeff, and R. E. Clark, "College cheating: Immaturity, lack of commitment, and the neutralizing attitude," Res. High. Educ., vol. 25, no. 4, pp. 342-354, 1986, DOI: 10.1007/BF00992130.

[28] G. M. Diekhoff, E. E. LaBeff, R. E. Clark, L. E. Williams, B. Francis, and V. J. Haines, "College cheating: Ten years later," Res. High. Educ., vol. 37, no. 4, pp. 487-502, 1996, DOI: 10.1007/BF01730111.

[29] K. O. Jones, J. Reid, and R. Bartlett, "E-learning and E-cheating," presented at the 3rd E-Learning Conference, Coimbra, Portugal, 2006, pp. $45-48$.

[30] K. O. Jones, J. Reid, and R. Bartlett, "E-learning and E-cheating," Commun. Cogn. Monogr., vol. 41, no. 1-2, pp. 61-70, 2008.

[31] K. O. Jones, J. Reid, and R. Bartlett, "Cyber Cheating in an Information Technology Age," Digithum, no. 10, pp. 19-28, 2008, DOI: $10.7238 /$ d.v0i10.508.

[32] Z. Ercegovac and J. V. Richardson, "Academic Dishonesty, Plagiarism Included, in the Digital Age: A Literature Review," Coll. Res. Libr., vol. 65 , no. 4, pp. 301-318, Jul. 2004, DOI: 10.5860/crl.65.4.301.
[33] M. Bouville, "Why is Cheating Wrong?," Stud. Philos. Educ., vol. 29, no. 1, pp. 67-76, Aug. 2009, doi:10.1007/s11217-009-9148-0.

[34] R. R. Gajewski, "IT in Educational Management: Can it Support Solution of e-Cheating Problem?," presented at the SAITE 2016, Minho, 2016.

[35] H. Zhou and S. S. Lan, "A Comparative Analysis On Students' Perceptions And Attitudes Towards Academic Dishonesty Between Students In China And In The United States," in Proceedings of the Spring 2007 American Society for Engineering Education IllinoisIndiana Section Conference, 2007.

[36] Z. Khan and S. Subramanian, "Students go click, flick and cheat... e-cheating, technologies and more," J. Acad. Bus. Ethics, vol. 6, pp. 126, 2012.

[37] G. G. Ravasco, "Technology-Aided Cheating in Open and Distance e-Learning,” Asian J. Distance Educ., vol. 10, no. 2, pp. 71-77, 2012.

[38] G. G. Ravasco, "Technology-Aided Cheating in ODeL: What Else Do We Need to Know?," in Creating Spaces and Possibilities, 2012.

[39] J. Sheard, M. Dick, S. Markham, I. Macdonald, and M. Walsh, "Cheating and plagiarism: perceptions and practices of first year IT students," ACM SIGCSE Bull., vol. 34, no. 3, pp. 183-187, 2002, DOI: $10.1145 / 544465.544468$

[40] J. Sheard and M. Dick, "Computing student practices of cheating and plagiarism: a decade of change.," in The 16th Annual SIGCSE Conference on Innovation and Technology in Computer Science Education, ITiCSE 2011, Darmstadt, Germany, June 27-29, 2011, 2011, pp. 233-237, DOI: 10.1145/1999747.1999813.

[41] R. Likert, "A Technique for the Measurement of Attitudes," Arch. Psychol., no. 140, pp. 1-55, 1932.

[42] M. Spitzer, Digitale Demenz. Droemer Knaur, 2012.

[43] M. Spitzer, The Mind within the Net: Models of Learning, Thinking, and Acting, 1st edition. The MIT Press, 1999.

[44] L. Dossey, "FOMO, digital dementia, and our dangerous experiment," Explore N. Y. N, vol. 10, no. 2, pp. 69-73, Apr. 2014, DOI: 10.1016/j.explore.2013.12.008.

[45] R. R. Gajewski, "How to change the unchanging? Restructuring Polish universities for the XXI century," in TelE-Learning, D. Passey and M. Kendall, Eds. Springer US, 2002, pp. 297-300.

[46] K. Illeris, Three Dimensions of Learning: Contemporary Learning Theory in the Tension Field Between the Cognitive, the Emotional and the Social. Malabar, Florida: Krieger Publishing Company, 2004.

[47] G. Cheetham and G. Chivers, "How professionals learn in practice: an investigation of informal learning amongst people working in professions,” J. Eur. Ind. Train., vol. 25, no. 5, pp. 247-292, 2001, DOI: $10.1108 / 03090590110395870$. 